\title{
TRADUTORES, INTÉRPRETES OU PROMOTORES DE MUDANÇA? Cientistas sociais, educação sanitária rural e resistências culturais (1940-1960)
}

\author{
Marcos Chor Maio* \\ Nísia Trindade de Lima**
}

\begin{abstract}
Resumo: Este trabalho objetiva analisar as relações entre ciências sociais e saúde pública no Brasil, privilegiando o papel de sociólogos e antropólogos que se colocaram na posição de "tradutores" entre os profissionais de saúde e as populações rurais objeto da ação de organismos governamentais. Educação sanitária, saneamento, profilaxia e medicina curativa, medicina preventiva passam a ser percebidos como ações cuja eficiência dependia diretamente do profundo entendimento de um universo mais amplo e complexo que a realidade concreta, ou seja, o universo cultural. Neste ponto reside a posição central dos cientistas sociais no planejamento das ações administrativas voltadas especialmente para a população rural brasileira: o seu conhecimento das questões de natureza sociocultural deveria antecipar e orientar quaisquer intervenções.
\end{abstract}

Palavras-chave: pensamento social; história das ciências sociais; Brasil; Serviço Especial de Saúde Pública; desenvolvimento; sociologia rural.

\footnotetext{
Doutor em Ciência Política pelo Iuperj, pesquisador titular e professor do Programa de Pós-Graduação em História das Ciências e da Saúde da Casa de Oswaldo Cruz (Fiocruz) e vice-líder do Grupo de Pesquisa do CNPq "Ciência, saúde e pensamento social”. E-mail: maio@coc.fiocruz.br

** Doutora em Sociologia pelo IUPERJ, pesquisadora titular e professora do Programa de Pós-Graduação em História das Ciências e da Saúde, n Casa de Oswaldo Cruz (Fiocruz), e líder do Grupo de Pesquisa do CNPq "Ciência, saúde e pensamento social". E-mail: lima@coc.fiocruz.br
}

Recebido em 12 jul. 2009 e aprovado em 14 set. 2009. 


\section{Introdução}

Em carta a Henrique Maia Penido, médico e superintendente do Serviço Especial de Saúde Pública (Sesp), os cientistas sociais Luiz Fernando Raposo Fontenelle e Carlos Alberto de Medina, pertencentes à Divisão deEducação Sanitária, procuraram sensibilizar a direção da instituição quanto à importância das Ciências Sociais para o entendimento mais amplo dos problemas médicos. Em suas palavras:

A Saúde Pública (...) esbarra frequentemente - em países cuja formação se assemelha a do Brasil - com graves problemas de natureza social e econômica e cria, quase sempre, incompatibilidades entre o grupo de profissionais com ideais da medicina científica dos centros urbanos e as noções de saúde e doença das populações desfavorecidas (...). As causas culturais que dificultam e prejudicam a ação da medicina científica só podem ser caracterizadas pelas técnicas e conhecimentos que são objeto das Ciências Sociais. ${ }^{1}$

As tensões e os fracassos gerados por programas de saúde pública direcionados a populações rurais em diversas regiões do mundo foram diagnosticados por autoridades públicas, especialistas e, em particular, por antropólogos e sociólogos, durante as décadas de 1940 e 1950. Essas avaliações ocorreram especialmente no denominado Terceiro Mundo, no contexto da Guerra Fria, em período também marcado por propostas de modernização.

Desenvolvimento, planejamento, mudança provocada ou dirigida, e resistências à mudança são termos que formaram o léxico das discussões intelectuais e políticas no Brasil, após a segunda Guerra Mundial. Projetos para o país, expressão corrente no período, estavam por eles impregnados e eram apresentados por economistas, cientistas sociais, educadores e também por lideranças políticas e intelectuais da área da saúde, com especial destaque para as discussões sobre pobreza e obstáculos ao desenvolvimento. Entre os principais temas, ganhou relevo a aposta otimista na erradicação de doenças transmissíveis. 
Que relações se estabeleceram entre as Ciências Sociais e esses novos diagnósticos e projetos para o Brasil? Oferecer algumas respostas, ainda que parciais, para esta pergunta, consiste no principal objetivo deste texto. Considera-se importante a análise das continuidades e descontinuidades em relação às grandes linhas de interpretação do Brasil, que marcaram o período de 1910 a 1940, e do lugar ocupado pelas reflexões em torno da saúde neste processo. Algumas das imagens recorrentes sobre o país e seus males - como a metáfora do Brasil vasto hospital, cujos ecos se faziam sentir nos anos que se seguiram à Revolução de 1930 -, começavam a ser interpeladas nos novos tempos marcados pelo otimismo. Uma visão exemplar das novas perspectivas dos anos 1950 encontra-se no Programa de saúde pública do candidato, de Juscelino Kubitschek (1955), no qual se afirmava que o Brasil "não é só doença" (Hochman, 2008). O tom não era, contudo, plenamente otimista, pois nesse e em vários outros textos e documentos do período se constata a importância atribuída às endemias rurais e à resistência à medicina ocidental, vistas como um importante óbice ao esforço de desenvolvimento.

O principal argumento do mencionado texto da campanha de Juscelino Kubitschek expressava um mundo colonizado pela idéia de desenvolvimento no pós-Segunda Guerra Mundial, na interessante definição de Arturo Escobar (1998): os problemas de saúde da população brasileira a incapacitavam para o empreendimento urgente e necessário do desenvolvimento nacional. A leitura desse documento nos remete à complexa relação entre saúde e desenvolvimento, que não poderia ser reduzida a uma opção por um dos termos da polaridade: foco na melhoria das condições de saúde da população versus saúde como resultado do desenvolvimento do país (Farley, 2004), conforme apontou a bibliografia existente. Ecoam em suas propostas os argumentos de Gunnar Myrdal (1952) e Charles Winslow (1955), amplamente difundidos na primeira metade dos anos 1950, sobre a vigência de um círculo vicioso da doença e da pobreza e a necessidade de rompê-lo. 
De fato, a arena internacional, especialmente o papel de organismos de cooperação internacional na difusão dessas idéias e na definição da agenda de políticas públicas nacionais consiste em importante fator a ser analisado no período. No campo da saúde, a cooperação entre o Brasil e os Estados Unidos, que se estreitara durante os esforços de guerra, teve continuidade na atuação do Serviço Especial de Saúde Pública (Sesp). Este organismo, criado em 1942 pelos governos brasileiro e norte-americano para garantir condições de salubridade aos trabalhadores da borracha, no vale do Amazonas, e do minério de ferro, no vale do rio Doce, sofreria uma reorientação com o fim da Segunda Guerra Mundial, quando seu foco de atuação se deslocou para ações no interior do País envolvendo a construção de hospitais, unidades de saúde e atividades de educação sanitária (Campos, 2006). Em 1953, foi criada a Seção de Pesquisa Social no âmbito da Divisão de Educação Sanitária e nela atuaram cientistas sociais brasileiros com formação em universidades norte-americanas, além de consultores da Escola Livre de Sociologia e Política (ELSP) e do Instituto de Antropologia Social, órgão vinculado à Smithsonian Institution, com a colaboração da Divisão de Saúde e Saneamento do Instituto de Assuntos Interamericanos (Campos, 2006; Pierson, 1987). Ao longo dos anos 1950, o Sesp tornou-se gradativamente um amplo órgão voltado para os problemas de saúde pública do Brasil. Dele participam os cientistas sociais Kalervo Oberg, José Arthur Rios, Luiz Fernando Fontenelle e Carlos Alberto Medina. A ciência social então praticada enfatizava a importância do desenvolvimento de comunidades rurais para o processo de mudança social.

Este trabalho objetiva analisar as relações entre ciências sociais e saúde pública no Brasil, privilegiando o papel de sociólogos e antropólogos que se colocaram na posição de "tradutores" entre os profissionais de saúde e as populações rurais, objeto da ação de organismos governamentais. Educação sanitária, saneamento, profilaxia e medicina curativa, medicina preventiva passam a ser percebidas como ações cuja eficiência dependia diretamente do 
profundo entendimento de um universo mais amplo e complexo do que a realidade concreta, ou seja, o universo cultural. Neste ponto reside a posição central dos cientistas sociais no planejamento das ações administrativas voltadas especialmente para a população rural brasileira: o seu conhecimento das questões de natureza sociocultural deveria antecipar e orientar quaisquer intervenções.

A defesa de tal papel estava relacionada à discussão sobre as chamadas culturas de folk, conceito do antropólogo norte-americano Robert Redfield, amplamente difundido nas ciências sociais, tanto nos Estados Unidos como na América Latina, durante as décadas de 1940 e 1950. No Brasil, tal discussão apresentou-se, entre outros, em textos de Florestan Fernandes e Emilio Willems, nos quais temas como atraso cultural e resistências à mudança foram abordados, e entre os quais esteve presente, como problema, a difusão da medicina ocidental. Também expressa a importância atribuída a questões de saúde e à medicina popular pelas ciências sociais, o livro Medicina rústica, de Alceu Maynard Araújo, vencedor do Prêmio Brasiliana, em 1959, e que resultou de pesquisa realizada a convite de Donald Pierson no vale do São Francisco. A circulação e o reconhecimento de tais textos indicam que preocupações desse teor não se restringiram aos cientistas sociais que atuaram em instituições voltadas à intervenção no setor específico da saúde, como foi o caso do Sesp. É o que nos propomos a apresentar na primeira seção deste trabalho.

A segunda parte está dedicada às ciências sociais praticadas no Sesp, durante a década de 1950. Uma hipótese a ser demonstrada no curso da pesquisa que vimos realizando consiste na importância de registros e textos de cientistas sociais que não compõem o corpus mais valorizado na história das ciências sociais brasileiras, mas que tiveram peso importante na difusão de argumentos sociológicos em outros campos de conhecimento e prática, como: a saúde pública, a nutrição, a educação e o serviço social. Ademais, os debates no 
campo da saúde, da educação sanitária e do desenvolvimento rural podem contribuir para uma visão mais atenta à complexidade dos processos sociais em curso no Brasil das décadas de 1940 a 1960 e para maior compreensão das características da imaginação social e política no período.

\section{Cultura de folk, resistências culturais à mudança e medicina rústica: perspectivas das ciências sociais}

Uma incursão mais aprofundada sobre esses conceitos deveria, em princípio, levar-nos a uma contextualização mais ampla sobre as ciências sociais nas décadas de 1940 e 1950, com atenção para a sua institucionalização universitária, objeto de importantes estudos (Miceli, 1989) e para a realização de grandes projetos de pesquisa, envolvendo cientistas sociais estrangeiros e brasileiros, inclusive de diferentes regiões do País, e conformando novos padrões de trabalho acadêmico e novas redes de sociabilidade (Corrêa, 1987, Maio, 1999). Entretanto, em face dos limites desta apresentação e de seu objetivo principal - a análise das ciências sociais no Serviço Especial de Saúde Pública - optamos por apresentar as perspectivas de Florestan Fernandes e Emílio Willems, a partir de dois textos muito expressivos de suas respectivas posições. Sem preocupação com a ordem cronológica de publicação, consideramos oportuno iniciar essas reflexões pelo trabalho do primeiro.

Em 1946, Florestan Fernandes publicou no Jornal de São Paulo uma série de dez artigos sob o título "Um retrato do Brasil", nos quais comentava o livro Viagem ao Tocantins, do médico Júlio Paternostro. O autor, em diálogo com seu público, esclarece as razões para o título, bem como para suas motivações:

O leitor gostaria, naturalmente, de saber por que escolhi o título geral dos estudos desta série - Um retrato do Brasil. Sua curiosidade deve ter aumentado, já que não tratei do Brasil, em geral, mas simplesmente comentei os dados apresentados em Júlio Paternostro 
em Viagem ao Tocantins. A resposta é singela: em seu conjunto, os vários aspectos que foram sucessivamente analisados (...) dãonos de fato um retrato do Brasil. Daquele Brasil que está longe dos nossos olhos, afastado das nossas preocupações diárias, porém um Brasil que existe... (Fernandes, 1979, p.161).

Por sua vez, o livro de Paternostro, publicado na Coleção Brasiliana, em 1945, reuniu as observações do médico em duas viagens realizadas no vale do Tocantins, como integrante do Serviço de Febre Amarela pelo Convênio da Divisão Internacional de Saúde Pública da Fundação Rockefeller. De novembro de 1934 a março de 1935, Paternostro viajou pelo sudoeste e pelo centro de Goiás e, posteriormente, de maio a setembro de 1935, realizou sua segunda viagem, com o objetivo oficial de conhecer a distribuição da imunidade da febre amarela na região. Seus resultados consistiram em uma das principais fontes para o artigo de Fred Soper - "The geographical distribution of imunity to yelow fever in man of South América" (1937). Soper analisou nesse texto dados levantados na América Latina por médicos de diferentes nacionalidades, com o objetivo de identificar casos da doença em áreas onde estava ausente o único vetor até então reconhecido, o mosquito Aedes aegypiti, responsável pela sua transmissão em áreas urbanas.

A viagem de Paternostro inseria-se, desse modo, no esforço de pesquisa que tivera início em 1932, após a epidemia de febre amarela no vale do Canaã, no Estado do Espírito Santo. Ainda que a hipótese da transmissão da doença por outros vetores e em ambientes não urbanos fosse levantada desde 1914, foi na década de 1930 que se intensificaram os estudos sobre a febre amarela silvestre (Benchimol, 2001, Lowy, 2006). Ao se examinar a produção científica de Soper, pode-se verificar a importância atribuída à coleta de sangue e à captura de mosquitos em diferentes países da América Latina com o objetivo de analisar a manifestação silvestre da doença, e foi essa intenção que tornou possível a viagem e posterior publicação do livro de Júlio Paternostro. Contudo, a despeito de sua relevância 
científica do ponto de vista biomédico, não foi essa atividade que o médico brasileiro mais realçou em sua obra, mas sim o conhecimento geográfico e sociológico das regiões por ele percorridas e o seu encontro com os "párias da civilização" (Paternostro, 1945, 20).

E foi também por essa característica que, em "Um retrato do Brasil”, Florestan Fernandes (1979) se apoiou naquela fonte para discutir o significado da oposição entre litoral e sertão e indicar a necessidade de pesquisas feitas por especialistas sobre as populações e as relações sociais no interior do país. Ressaltou o fato de o trabalho de Paternostro ser um trabalho "interessado", motivado pelas convicções socialistas do médico, o que conferia um caráter de denúncia ao livro, que via como aspecto positivo, a despeito de apontar simplificações, omissões e superficialidade no tratamento de algumas questões.

O sociólogo observou a pouca nitidez geográfica dos termos litoral e sertão que apareceriam na verdade como expressão de certo tipo de formação social e cultural na qual o tempo, mais precisamente os contrastes entre várias fases históricas de uma civilização, seria variável mais significativa que o espaço. Não se tratava de distância geográfica, mas de distância cultural que se manifestava nos contrastes, ou, no limite, nos antagonismos e conflitos, entre civilização e "culturas de folk" (Fernandes, 1979, 123). Para ele, a oposição indicaria um gradiente de civilização:

O desenvolvimento sociocultural do Brasil não foi uniforme ou orgânico. Algumas cidades acompanharam o "progresso" da civilização, embora retardadamente; transformaram-se hoje, como São Paulo, em metrópoles. Outras, quando não regrediram, imobilizaram-se, estacionaram em seu processo sociocultural, como as chamadas 'cidades mortas'.... Estas formariam as 'culturas de folk'. (Fernandes, 1979, p.124).

Conformados pela tradição, milhares de indivíduos viviam a vida dos séculos XVIII ou XIX e, no contato entre o civilizado do 
litoral e o homem sertanejo, o "pária da civilização", como o chamou Paternostro (1945), as atitudes variavam da simpatia à rejeição, mas eram marcadas por inegável etnocentrismo. E numa frase de forte apelo simbólico, Florestan Fernandes afirma (1979, p. 125) que "a realidade cultural do Brasil é e será ainda durante alguns anos a descrita por Euclides da Cunha em Os Sertões".

Ao analisar as condições de vida no vale do Tocantins, Fernandes extrai do relatório de viagem observações referentes à educação, à saúde e ao trabalho. No que diz respeito à primeira, registra os exemplos de alienação e incongruência das escolas em relação ao meio social, o que se constituiria num fator a mais de reforço ao fenômeno de "demora cultural". O problema da escola que ensina a "ler, escrever e contar" e nada tem a dizer sobre as coisas do trato da terra e dos animais, e que, ou teria um efeito nulo sobre as populações, ou contribuiria para o êxodo rural, tema frequente entre os educadores, é retomado pelo sociólogo. Florestan Fernandes reporta-se à proposta de Fernando de Azevedo ao I Congresso Brasileiro de Escritores, realizado em 1945, no qual o educador defendeu a tese da "democratização da cultura."

$\mathrm{O}$ excessivo otimismo dos que atribuíam às soluções para os problemas educacional e sanitário a chave para resolver os obstáculos à modernização do País é contestado por Florestan Fernandes. No que se refere às condições de saúde retratadas por Paternostro, após chamar a atenção para as principais doenças, especialmente para a onipresença da malária, o sociólogo convida o leitor a refletir sobre o que considera valioso, tanto do ponto de vista médico como sociocultural: as relações entre medicina popular, ou "empírica", termo utilizado por ele, e a medicina científica. Elas seriam particularmente importantes "no estudo dos padrões de comportamento de uma cultura de folk e mesmo de certos aspectos da organização social (...) e úteis na análise dos motivos de aceitação ou rejeição de formas conhecidas de cura e tratamento das doenças 
- a relativa à 'medicina científica' representada pelos médicos" (Fernandes, 1979, p.140).

Ao considerar as trocas culturais, Fernandes observa que mesmo os médicos se ressentiam da "demora cultural", dadas as condições de isolamento em que permaneciam, e estavam também vulneráveis aos efeitos da cultura de folk. Destaca finalmente a proposta de Júlio Paternostro que defendia a utilização sistemática de curandeiros e "entendidos", após algum treinamento com os médicos, na transmissão de informes e aplicação de medicamentos, o que revelava uma boa compreensão do médico sobre o complexo cultural que envolvia a prática médica e requeria o desenvolvimento de uma "política etnológica" (Fernandes, 1979, p. 146).

Para o sociólogo, o texto de Paternostro reúne dados importantes sobre as condições de vida e trabalho, destacando os vários tipos de trabalhadores sertanejos — "os seringueiros, os vaqueiros, os remeiros, os carregadores, os apanhadores de castanha, os tropeiros..." (p. 148). Observa a mobilidade entre algumas dessas categorias de trabalhadores, o que se expressava inclusive na linguagem mista dos barqueiros-vaqueiros. Dá ênfase aos contratos verbais, à ausência de legislação do trabalho para os trabalhadores rurais no Brasil e à baixa remuneração. A instabilidade demográfica de alguns povoados e o nomadismo dos moradores são aspectos igualmente ressaltados.

A modernização requeria recursos racionais de pensamento e ação e esbarrava em obstáculos de natureza cultural. Em sua compreensão, as condições em que se deu o desenvolvimento demográfico, econômico e político do País colocaria alguns problemas específicos às possibilidades de se promover uma "mudança dirigida". O grau de descontinuidade econômica e cultural existente entre as cidades do litoral e o sertão, sobretudo, teria criado obstáculos à racionalização administrativa e política para a qual o governo não estaria preparado. Dessa forma, é sob a 
ótica das resistências à mudança que o livro de Paternostro desperta o interesse do sociólogo. Este último tema está presente em vários outros textos de Florestan Fernandes, pois, como afirma Maria Arminda do Nascimento Arruda (1996, p. 13), “... o que marca indelevelmente a produção de Florestan e atesta a originalidade da sua reflexão é a análise da transformação, mas, sobretudo, o relevo conferido aos entraves à modernização brasileira. São os empecilhos que conferem o tom dominante da discussão".

Em suas conclusões, Florestan Fernandes (1979, p. 163) observa que todos os seus comentários à obra do médico referiram-se a "desajustamentos e conflitos provocados pela difusão da medicina, da assistência médico-sanitária e hospitalar, do ensino primário, etc.". Ou seja, estariam relacionados à introdução de elementos culturais da "civilização" naquelas sociedades de "folk" do vale do Tocantins. Segundo o autor, o livro de Paternostro revelaria "a diferença que existe entre o processo orientado ou dirigido de alguma forma por meio de técnicas sociais e a mudança sociocultural espontânea."

Tratava-se, em síntese, de defender a adoção pelo governo e pelas administrações locais de técnicas sociais, informadas por trabalhos de especialistas da área de ciências sociais, capazes de subsidiar "uma política de controle e orientação, na medida do possível, dos processos sociais" (Fernandes, 1979, p. 164). O sociólogo afirma que o problema da intervenção e do controle sobre processos sociais era constitutivo das ciências sociais que, em suas palavras, "nasceram e desenvolveram-se, sob o signo de Augusto Comte ou sob o signo de Karl Marx - com o duplo propósito do conhecimento exato da realidade social e de seu domínio pelo homem" (p. 161).

A defesa do não diletantismo seria também tributária da perspectiva de Karl Mannheim, e, em outros textos de Florestan Fernandes coetâneos ao aqui comentado, são frequentes as referências 
a esse sociólogo cujas idéias alcançaram ampla repercussão nas décadas de 1940 e 1950, no Brasil (Villas Bôas, 2006). Como observou Gláucia Villas Bôas, a recepção de Mannheim no país foi marcada pela defesa do papel dos cientistas sociais na transição de uma sociedade tradicional para uma sociedade moderna, algo que, se esteve distante das preocupações teóricas ou mesmo práticas do sociólogo alemão, marcou de modo indelével a produção sociológica brasileira no período a que vimos nos referindo. Também por essa razão e, em diálogo com a proposta de Luiz Werneck Vianna sobre orientações mertonianas ou mannheimeanas nas ciências sociais, a autora observa que tanto os intelectuais cariocas como os paulistas formaram uma geração de mannheimeanos (Villas Boas, 2006). No caso de Florestan Fernandes (1976), tal perspectiva se evidencia na defesa de técnicas sociais capazes de promover uma intervenção racional nos processos de mudança.

"Um retrato do Brasil" foi publicado posteriormente na livro Mudanças sociais no Brasil, que reuniu, em sua primeira edição, textos escritos entre 1943 e 1959. No prefácio a essa obra, Fernandes (1979, p. 11) lembrou a importância dos trabalhos de Emílio Willems, a partir dos quais se evidenciou que "culturas diversas coexistem na sociedade brasileira, dentro das mesmas fronteiras políticas". Cita, em particular, um trabalho de Willems, O problema rural brasileiro do ponto de vista antropológico, publicado pela Secretaria da Agricultura, Indústria e Comércio do Estado de São Paulo, em 1944.

Nosso interesse pelo texto foi despertado pela forma muito clara com que o sociólogo defende um programa de intervenção política nas "culturas sertanejas", baseado em especialistas de diferentes áreas e com forte peso das ciências sociais. $\mathrm{O}$ trabalho foi e, ao longo da argumentação apresentada, é uma inegável defesa do sentido político dos estudos de comunidades rurais, quer de imigrantes, quer das comunidades de "caboclos" ou "sertanejos". 
A idéia de cultura sertaneja, cultura cabocla ou cultura rústica, termos que se alternam, apresenta diferenças em relação às chamadas culturas de folk, algo distinto da perspectiva adotada por Florestan Fernandes que, ao que parece, não atribuía significado especial a tal distinção. Para o conceito de cultura cabocla, o contato interétnico representa importante papel, como podemos ver no seguinte trecho: "Quase todos os países latino-americanos têm suas culturas caboclas. Na África e na Oceania se encontram culturas primitivas ou semiprimitivas e os contatos que se estabelecem entre elas e os civilizadores brancos podem ser comparados - mutatis mutandis aos contatos que ligam a civilização litorânea no Brasil às culturas sertanejas" (Willems, 1944, p. 18).

A definição de cultura cabocla e suas diferenças em relação às tradicionais culturas camponesas européias referiam-se também ao nomadismo e à idéia do uso predatório da terra e dos recursos naturais: "O esgotamento das terras, associado a técnicas extensivas e a uma pressão demográfica relativa leva, necessariamente, ao seminomadismo e desapego à gleba, traço cultural esse que contrasta com a sedentariedade absoluta dos camponeses europeus" (Willems, 1944, p. 22).

O caboclo - designação que, de início, indicaria predominantemente o contato interétnico do branco português com o indígena - passa a se referir a um modo de vida: o "modo de vida caipira". A organização econômica do caboclo típico é précapitalista e, segundo o sociólogo, a única possível em determinadas circunstâncias. Esse princípio adaptativo não era muitas vezes aceito pelo imigrante que, com freqüência, fracassava. E muitas vezes "os 'italianos' e 'alemães' acaboclados sobreviveram e contribuíram para o povoamento dos sertões meridionais" (Willems, 1944, p. 10). Entre os exemplos arrolados por Willems, destaca-se a colônia Feliz, no Rio Grande do Sul, para onde se dirigiram imigrantes alemães, 
na década de 1840. Após problemas com a venda de milho e feijão, passaram a trabalhar apenas três dias por semana.

O problema das populações sertanejas encontrava-se no estágio pré-capitalista em que viviam, nas palavras de Willems, uma "existência vegetativa e autossuficiente." Tratava-se de propor intervenção em suas formas de vida que suscitasse novas necessidades e as integrasse à economia de mercado. Apenas o conhecimento oriundo das ciências sociais permitiria uma ação orientada no sentido de alterar práticas culturais de forma congruente com o meio em que se inseriam. A desconsideração em face desse universo cultural mais amplo poderia, no limite, gerar situações de miséria diante das quais seria "mil vezes preferível" a "existência vegetativa" das populações sertanejas, por mais que elas afrontassem o "espírito capitalista" (Willems, 1944, p. 12). ${ }^{2}$

O sertão figurava como locus da desintegração de culturas tribais e sua substituição por "culturas caboclas". É enfática a observação de Willems (1944, p. 35):

[...] Decerto, ninguém ficará surpreso com a observação de que as culturas camponesas da Europa apresentam um conteúdo mais rico e variado do que as culturas sertanejas do Brasil. Para muita gente, no entanto, constitui motivo de espanto o fato de que também a maioria das culturas tribais do Brasil central e setentrional esteja em condições relativamente mais favoráveis do que a de seus vizinhos caboclos.

Muitos dos erros cometidos na tentativa de desenvolver ações pedagógicas junto a populações sertanejas são atribuídos a medidas que consideravam inadequadamente seu contexto cultural. Retoma o tema da "escola de alfabetização" como um exemplo do que não se deveria fazer; apesar de o sociólogo não utilizar o termo, a idéia é que sua introdução provocaria um efeito anômico, pouco contribuindo para integrar a cultura sertaneja numa economia competitiva e em padrões de consumo e de vida considerados civilizados. O reformador 
sempre seria colocado diante de problemas extremamente complexos e os especialistas, que geralmente desenvolviam ações junto a essas populações, focalizavam um traço cultural ou o enxerto de uma inovação, não observando que o êxito dependeria da proporção em que outros elementos culturais pudessem ser substituídos (p. 17).

Willems (1944,p. 13) considera que um dos elementos básicos, o regime de trabalho, está quase sempre associado a concepções do tempo, à alimentação, à organização da família, à religião e às atividades recreativas. Defende, por fim, a presença de cientistas sociais nos processos de mudança dirigida, além dos tradicionais especialistas envolvidos em projetos para as populações caboclas: médicos sanitaristas, agrônomos, educadores e economistas: “[...] os observadores são quase sempre especialistas interessados, por exemplo, em curar a maleita, em difundir o cultivo da batatinha, em implantar hábitos profiláticos contra a ancilostomíase, em estudar as possibilidades do crédito ou da organização de cooperativas, os processos básicos passam despercebidos" (p. 15).

E, em outra passagem: "Para os médicos, o caboclo é um doente e um sub-alimentado; para o educador todo 'mal' reside no analfabetismo; o agrônomo verifica a inexistência de conhecimentos 'racionais' de agricultura; os economistas dão pela falta de crédito, de mercados e meios de comunicação; os moralistas desejam erradicar certos vícios e assim por diante" (Williams, 1944, p. 21).

Esses especialistas não poderiam ignorar o papel das ciências sociais, especialmente da Sociologia e da Antropologia - às quais se poderiam associar a ecologia, a Demografia e a Psicologia Social - na elaboração de planos científicos voltados à análise cultural e à organização do processo de transição para uma sociedade moderna. A tarefa seria das mais difíceis, pois,

infelizmente, os conhecimentos que se tem das nossas culturas sertanejas são mais do que escassos. Além de umas frases surradas 
sobre o contacto da civilização do litoral e do sertão, sobre a rarefação das populações sertanejas, sobre cangaceiros, gaúchos, Canudos, o Joazeiro de Pe. Cicero e mais uma dúzia de imagens literárias, gastas pelo consumo diário, pouquíssima coisa se sabe sobre a natureza das nossas culturas caboclas. Apenas se vislumbrou o abismo que as separa da civilização urbana e até hoje poucas foram as tentativas de subordinar a política educacional a um estudo prévio baseado nos métodos que a moderna análise cultural aconselha. (Williams, 1944, p. 28).

Dois deveriam ser os parâmetros nos processos de mudança dirigida entre essas populações: a "interrupção do processo multissecular de transmissão tradicional", seguida da substituição do antigo patrimônio por um novo, ajustado ao sistema econômico moderno; e a articulação do patrimônio cultural assim construído ao meio a que se deveria ajustar (Williams, 1944, p. 21). Eles deveriam orientar ações de que constituiria exemplo um plano de criação de internato agrícola, que estava em vias de ser fundado em São Paulo, e merece destaque no texto. Do ponto de vista de Emílio Willems, a proposta tinha aspectos positivos, mas deveria ser acompanhada de outras medidas que, de fato, garantissemuma mudança de mentalidade através da interrupção do processo "multissecular de transmissão tradicional". A ideia era afastar o educando de seu meio original, garantindo assim o corte com a experiência anterior. $\mathrm{O}$ retorno à comunidade poderia trazer, todavia, os antigos constrangimentos da cultura tradicional, muito reforçados pela família e pelas relações vicinais.

Talvez o imigrante representasse o tipo social que mais facilmente assimilaria os elementos considerados necessários à adaptação ao "sistema econômico moderno", pois o que se desejava evitar era o retrocesso após o retorno do educando a seu meio de origem. Tratava-se de impedir o "acaboclamento cultural desse novo tipo de povoador-modelo", o que só seria possível aliando à ação educacional outras formas de intervenção organizada”. Estudos sociológicos e antropológicos cumpririam nesse aspecto importante 
papel e se poderia seguir o exemplo dos Estados Unidos, onde especialistas em sociologia rural cooperavam com departamentos técnicos e administrativos do governo federal e dos governos estaduais na busca de solução para os problemas rurais (Williams, 1944, p. 29).

Tal princípio de intervenção, voltado no caso em pauta para as populações sertanejas, deveria orientar um programa de pesquisa em ciências sociais em que se combinassem pesquisa monográfica e estudos comparativos. Na verdade, a primeira deveria estar subordinada ao interesse de realizar os segundos, uma vez que, de acordo com Willems, esses é que permitiriam a formulação de leis científicas. Em concordância com Herskovits, afirmava a necessidade de se reconstruir, nos estudos de comunidade, de caráter monográfico, o background histórico das populações locais e orientá-los por questões que permitissem o posterior estabelecimento de comparações e um programa extensivo de pesquisas (Williams, 1944, p. 30).

Essa compreensão aparece de forma mais ou menos explícita em outros trabalhos de Emílio Willems, especialmente nos dedicados à aculturação e assimilação de imigrantes e sertanejos. Neles fica evidente a preocupação do autor em assegurar maior uniformidade cultural e desenvolver mentalidade congruente com a economia e vida social modernas. O debate sobre as distinções conceituais entre processos de aculturação e assimilação não deve ser visto, assim, como mero exercício diletante. A sua preocupação dirigia-se para aquilo que considerava como aspectos dinâmicos da mudança sociocultural, sobretudo no que dizia respeito ao cerne do conceito de assimilação: "processo sociopsíquico de transformação da personalidade" (cf. Willems, 1940, p. 31).

Da leitura dos livros de Willems sobressaem, de forma muito nítida, a natureza e o compromisso político das ciências sociais praticadas - inclusive, ou mesmo principalmente - nos estudos de 
comunidade. Uma das pesquisas mais conhecidas do autor, dedicada ao processo de mudança sociocultural em Cunha, cidade do interior de São Paulo, detém-se igualmente nas resistências à mudança, nas tensões entre tradição e transição para a vida moderna, com ênfase nos processos de desorganização, individualização e secularização (Willems, [1947] 1961, p. 15). ${ }^{3}$ Edson Carneiro observa, com acerto, que, nesse estudo de Emílio Willems, a cultura caipira aparece como pano de fundo do problema a que de fato se dedicava: o da mudança cultural (cf. Vilhena, 1996, p. 139).

O debate sobre processos de mudança sociocultural e o enfoque de possibilidades de manifestação de anomia entre as populações sertanejas acompanham outros estudos que se desenvolveram, ao menos em parte, sob inspiração dos trabalhos de Emílio Willems. Em outros textos tivemos a oportunidade de analisar o recurso ao conceito de cultura rústica em importantes linhas de pesquisa como as realizadas por Maria Isaura Pereira de Queiroz sobre campesinato e movimentos messiânicos no Brasil (Lima, 1999). Um dos mais sugestivos desdobramentos do conceito consistiu na proposição de uma Medicina rústica, por Alceu Maynard Araújo, professor da Escola Livre de Sociologia e Política e que participara com Donald Pierson do projeto de pesquisa no vale do São Francisco.

Vencedor do Prêmio Brasiliana, em 1959, o livro Medicina rústica documentou e analisou as práticas de cura e a visão sobre a medicina entre populações do Nordeste. De acordo com Araújo, na hierarquia que o povo estabelecia entre os que praticavam a medicina, o primeiro lugar era ocupado pelos curandeiros. Depois vinham os benzedores e benzinheiras (benzedoras de crianças), os doutores de raízes, os curadores de cobras, os farmacêuticos, e por último os médicos ou doutores. Ainda segundo o autor, poucos habitantes procuravam assistência médica, alegando que os médicos só receitavam penicilina e que não iam à casa de pobre. Analisando problemas de grande diversidade e complexidade, como as relações 
entre religião e práticas de cura, Medicina rústica tem, entre outros, o mérito de deslocar a atenção das "resistências culturais à mudança" para os equívocos dos que representavam a medicina ocidental.

No mesmo período em que Alceu Maynard Araújo executou a sua pesquisa, cientistas sociais do Serviço Especial de Saúde Pública realizaram atividades junto a profissionais de saúde e a populações rurais e registraram valiosas observações sobre a realidade com que tomavam contato e as dificuldades de seu papel como promotores de mudança.

\section{As ciências Sociais no Serviço Especial de Saúde Pública}

No início de 1954, o Boletim do Sesp trazia matéria intitulada "O Sesp e as ciências sociais", na qual informava que:

Uma das dificuldades que o Sesp vem constantemente encontrando é a de convencer o público a trocar os maus hábitos de saúde pelos bons. O povo não gosta de abrir mão de costumes que vem praticando por gerações (...).

É realmente um problema fazer com que o povo construa privadas, aceite a vacinação ou coma alimentos diferentes.

Eis quando a colaboração do cientista social é inestimável. Com um perfeito conhecimento da cultura do povo, de suas crenças, dos valores que preza e do seu modo de pensar, ele pode ajudar o serviço de saúde a desenvolver um melhor trabalho visando modificar o modo de vida. (Sesp..., 1954, p. 2).

O editorial do Boletim trazia uma síntese dos obstáculos enfrentados pelo programa de saúde do Sesp e destacava o papel a ser desempenhado pelo cientista social no processo de superação das resistências culturais à mudança social.

Desde o início da década de 1950, cientistas sociais na América Latina, com o apoio de agências norte-americanas, estiveram voltados 
para programas de "mudança social provocada" na área da saúde pública. No contexto do Pós-Guerra, da Guerra Fria e do processo de descolonização, o desenvolvimento tornou-se tema obrigatório. Em 1951, o Instituto de Assuntos Interamericanos, principal agência norte-americana de cooperação e assistência técnica em saúde em operação durante e após a Segunda Guerra Mundial, junto com o Instituto de Antropologia Social (ISA), unidade do Departamento de Etnologia Americana da Smithsonian Institution, fizeram um acordo que marcou o engajamento de antropólogos em programas de saúde na América Latina, caracterizando especialmente a associação das ciências sociais com o desenvolvimento do Terceiro Mundo (Register to.., [1952], p. 3). Esse período também se constitui num importante capítulo da história das ciências sociais aplicadas.

Em meados de 1950, George Foster, diretor do ISA, coordenou um conjunto de pesquisas na Colômbia, México, Peru e Brasil sobre centros de saúde sob o patrocínio do governo norte-americano. Fizeram parte também do projeto os antropólogos Charles Erasmus, Ozzie Simons, Kalervo Oberg e Isabel Kelly (Foster, 1951).

O relatório, publicado em 1951, dedicou especial atenção às relações entre a população e os centros de saúde nos diversos países. Tratava-se de um projeto de "engenharia humana", nas palavras de Foster, ou engenharia social, em que a participação de cientistas sociais "poderia contribuir para o sucesso de programas de assistência técnica ao analisar o comportamento da população envolvida e ao chamar a atenção dos administradores sobre os meios aos quais os padrões tradicionais de ação podem facilmente ser modificados e acerca daqueles que são mais fortemente resistentes" (Foster, 1951, p. 2).

Os cientistas sociais envolvidos no programa verificaram que a medicina popular exercia grande influência sobre a população implicando, assim, reduzida frequência desta aos centros de saúde. 
O grande desafio seria a sensibilização da população ao uso da medicina científica ou moderna (Foster, 1951).

O breve quadro apresentado acima constitui-se numa espécie de pano de fundo das preocupações que, em 1953, levaram à criação da Seção de Pesquisas Sociais do Sesp, órgão vinculado à Divisão de Educação Sanitária, sob a direção do sociólogo José Arthur Rios, que fora coordenador da Campanha Nacional de Educação Rural (CNER), no início dos anos 1950. Ele fez mestrado em Sociologia Rural na Universidade de Louisiana, sob a orientação de T. Lynn Smith, sociólogo norte-americano conhecido no Brasil, especialmente nas décadas de 1940 e 1950 (Valladares, 2005).

A Divisão de Educação Sanitária do Sesp foi criada em 1944 e coordenada pelo antropólogo Charles Wagley, um dos idealizadores do programa de educação em saúde daquele organismo. Wagley, que realizava pesquisas no Brasil desde os anos 1930, integrava naquela ocasião os quadros administrativos do Sesp. Ao longo de três anos e meio, ele foi do staff da instituição exercendo as seguintes funções: diretor do programa de migração para a Amazônia, coordenando os serviços médicos destinados à população que se deslocava para trabalhar na região; assistente do superintendente do Sesp; e, diretor da Divisão Sanitária (Wagley, 1953, p. viii).

A partir dos anos 1950, quando o Sesp expandiu suas atividades, houve a incorporação de cientistas sociais à instituição, dedicados à educação sanitária. O sociólogo José Arthur Rios publicou dois artigos no Boletim do Sesp, órgão de ampla circulação no interior da instituição, que refletem as preocupações que deveriam caber às ciências sociais na interface com a saúde pública.

No primeiro artigo, intitulado "Ciências sociais e saúde pública", Rios aborda o papel do sociólogo nos programas de saúde pública. Não se trata de atribuir ao cientista social o papel de administrador ou político assim como o de reformista social. 
Quando ele é capturado por uma dessas funções, perde o sentido crítico de sua atividade que deve ser exercida sem preconceitos. Cabe ao sociólogo ter ascendência sobre o administrador, lembrando a posição do antropólogo George Foster.

As extremas desigualdades existentes no país, segundo Rios, refletem-se também no âmbito da saúde. Elas se tornam um desafio para os agentes de saúde que lidam com a populaçãoalvo. Eles partem de conceitos e valores totalmente distintos da sociedade local, o que, frequentemente, gera mal-entendidos. Neste sentido, o sociólogo deve, portanto, servir de intérprete, de tradutor "[d]a cultura do assistido nos termos racionais e científicos do grupo cultural que o administrador representa" (Rios, 1953). Só essa "tradução" seria eficaz à mudança cultural pretendida, ou seja, à transformação global do sistema de valores da população, especialmente a pertencente ao mundo rural. Para isso, Rios propõe o "desenvolvimento de comunidade". No plano da saúde pública, mediante a "organização social da comunidade e da sua estrutura local de liderança, o sanitarista pode, com maior eficácia, infundir na população rural novos hábitos e valores" (Rios, 1953).

No segundo artigo, "A saúde como valor social", Rios discorre sobre a concepção de saúde compartilhada pelos cientistas sociais. Estes a concebem inserida num contexto cultural particular. Interpelando aqueles que consideram indivíduos ou grupos como "tábua rasa na qual podemos inscrever tudo que desejamos", o autor alerta o médico ou o sanitarista quanto ao desejo de mudar os hábitos de uma coletividade lembrando que as sociedades têm tradições culturais específicas. Em suas palavras:

o fato de certos indivíduos não possuírem o hábito de escovar os dentes ou do banho diário não significa que sejam destituídos de qualquer noção sobre saúde e doença. (...) Todas as coletividades (...) têm alguma noção acerca desses problemas e costumam exprimi-los, na sua tradição oral, sob a forma de adágios, provérbios, receitas, etc. Costumam ainda acontecer que essas noções estão ligadas a 
outros traços culturais, misturadas a técnicas de trabalho, a modos de vida, a crenças religiosas [a exemplo do feiticeiro, do shaman e do curandeiro]. (Rios, 1953a, p. 2).

Em 1954, como indica Rios em seu livro Educação de grupos, o Sesp utiliza o trabalho das "curiosas e estuda o meio de começar a utilizar os serviços dos curandeiros e curandeiras" (Rios, 1954, p. 175). O uso de valores e técnicas culturais locais pelo Sesp, como no caso das parteiras, estava associado à possível participação de membros da comunidade em processos de mudança de hábitos culturais. Como afirma o autor:

À primeira vista, o curandeiro pode parecer inimigo irreconciliável do médico. Em certos casos, principalmente em cidades já desenvolvidas, onde o curandeiro é um charlatão convicto, o médico deve combatê-lo energicamente. Nas zonas rurais, porém, em presença da chamada "cultura de folk" a atitude deve ser diferente porque, na maioria dos casos, o médico está defrontando um líder tradicional, convicto de suas técnicas, prestigiado pelo grupo e que pode ser transformado em precioso auxiliar. Através do curandeiro, o médico se familiariza com a medicina popular e pode harmonizar a introdução de novas práticas com a preservação do que é útil, ou, pelo menos inócuo no receituário do povo. Por sua vez, o curandeiro, quando não é fanático ou charlatão, vai percebendo a vantagem de substituir as benzeduras pela injeção, as hervas pela penicilina. (Rios, 1954, p. 216-217).

Na visão de Rios, o educador sanitário deve estar atento ao "lastro cultural" dos diversos grupos sociais. A recepção de novas práticas médicas não ocorre em ambiente necessariamente favorável. Ele deve "vencer resistências culturais, remover práticas já radicadas na estrutura dos hábitos, cristalizadas em atitudes. Não se trata de escrever novas palavras num livro em branco, mas de raspar caracteres já gravados pelo penetrante estilete da tradição cultural" (Rios, 1954). Assim, para que a saúde venha a ser um valor social no Brasil, caberia desenvolver o trabalho de educação das comunidades. Neste caso, a tarefa do educador estaria na dinamização "dessas comunidades paralisadas pela inércia e pela rotina cultural" 
(Rios, 1954). Como se pode observar, a mudança social deveria ser concebida pelos atores no campo da saúde como algo inexorável, uma importante marca da sociologia dos anos 1950.

O antropólogo Luiz Fernando Raposo Fontenelle também fez parte da Seção de Pesquisas Sociais do Sesp. Formado em História e Geografia pela Faculdade Nacional de Filosofia em 1950, Fontenelle estagiou no Museu do Índio e, em seguida, no Conselho Nacional de Geografia. Em 1953, iniciou estágio no Museu Nacional, por meio da antropóloga Heloísa Alberto Torres, onde teve estreito contato com o antropólogo Carl Withers, mais conhecido como James West, autor de Middletown, um clássico dos estudos de comunidade. Em 1955, ele foi admitido no Sesp. Em meados dos anos 1950, Fontenelle fez mestrado em Saúde Pública na Universidade da Califórnia, sob a orientação do antropólogo George Foster. ${ }^{4}$

Em função de uma série de tensões entre a equipe do Sesp e a população, o antropólogo realizou uma avaliação do trabalho da instituição em Aimorés, Espírito Santo. O objetivo principal do estudo era a análise do uso da medicina popular, as visões sobre saúde e doença presentes na população e uma pesquisa acerca da qualidade das interações entre a unidade sanitária local do Sesp e a população (Fontenelle, 1959, p. 7). Buscou-se, ainda, com o conhecimento do sistema de medicina popular, oferecer subsídios à ação dos centros de saúde pública (p. 9).

A pesquisa, realizada em município de médio porte $(37.000$ habitantes) na região do Vale do Rio Doce, em Minas Gerais, desenvolveu-se por meio de entrevistas, observação participante, visitas a diversas localidades - otimizadas pelos arquivos da unidade de saúde, que continham os questionários preenchidos pelas visitadoras sanitárias (p. 7).

Fontenelle procura demonstrar as diferenças existentes entre a medicina científica e a medicina popular buscando assim revelar a 
coerência existente no sistema terapêutico existente entre a população pobre. Sua etnografia apresenta os motivos da adesão a certos tratamentos, a caracterização dos responsáveis pelos tratamentos, os sistemas de cura marcados pela tradição local que envolvia, ainda, o mundo mágico. $\mathrm{O}$ antropólogo conclui que

"o estudo da Medicina Popular de Aimorés revela claramente a existência de um corpo de conceitos cuja composição influencia a aceitação ou a recusa dos preceitos e das técnicas da Medicina Científica. (...) O sangue como elemento essencial e a fonte da vida, cuja contaminação é motivo para as mais variadas moléstias, a doença encarada apenas pelas suas manifestações mais evidentes, a rapidez exigida a todos os processos de cura, os conceitos de "frio" e "quente", "forte" e "reimoso", vinculando-se a doenças e também a hábitos alimentares, a suposição de que a persistência de uma ferida ou enfermidade é motivada por feitiçaria, as linhas gerais em que são colocadas as noções do sobrenatural constituem, a grosso modo, os caracteres centrais e constantes da estrutura de Medicina Popular. (Fontenelle, 1959, p. 73-74).

A segunda parte do trabalho aborda as relações entre a população de Aimorés e a unidade de saúde do Sesp cujo alvo são as gestantes e as crianças da localidade e está centrado no trabalho de caráter preventivo. A relação entre a unidade de saúde e a população era de "aberta hostilidade" (Fontenelle, 1959, p. 7). A falta de conhecimento mútuo seria a primeira característica da relação entre médicos e pacientes na unidade. Estes desconheciam as técnicas e os processos terapêuticos dos médicos, que, por sua vez, ignoravam as práticas da medicina popular.

Uma das entrevistas de Fontenelle (1959, p. 38) com um técnico da unidade do Sesp mostrou que, frequentemente, os pacientes não lhes revelavam outros detalhes do seu estado por receio dos "gritos" de reprovação que estes técnicos e médicos davam. Esta abordagem agressiva dos médicos acabava dificultando ainda mais o trabalho (p. 80). Em uma situação de parto, por exemplo, ao contrário da parteira que permanecia todo o tempo com a parturiente (relação 
de familiaridade), os médicos aos quais ela era confiada no hospital eram completamente estranhos, uma das razões da preferência quase absoluta pelos partos realizados em casa, juntamente com a possibilidade de continuar administrando o lar (p. 94-95).

Fontenelle (1959, p. 76) chama a atenção para o fato de que a formação dos profissionais que atuavam na unidade de saúde acompanhava as técnicas e valores culturais dos grandes centros urbanos, em descompasso com a realidade rural em que pretendiam atuar. Havia duas importantes formas de atuação da unidade sanitária na comunidade: uma de base mais pessoal, através das visitadoras, responsáveis pela verificação das condições gerais das crianças, gestantes, mas também para ministrar conselhos sanitários à população. Este processo requeria certo grau de familiaridade com os moradores do município para que se adquirisse maior confiança e aceitação de seus conselhos, o que nem sempre acontecia. A rotatividade desses profissionais entre as unidades contribuía para que as visitadoras se tornassem personagens estranhos à comunidade (p. 83). A distância geográfica da unidade até os locais de moradia dos mais pobres dificultava a locomoção e, por conseguinte, a frequência ao Sesp.

Fontenelle julga que a saída para os problemas enfrentados pela unidade de Saúde passa por um processo de desenvolvimento de Aimorés que se traduziria por um "longo programa de reabilitação econômica e social da população pobre de Aimorés, (...) um alargamento do mercado de trabalho, maiores oportunidades para ascender socialmente" e uma ação educativa intensiva, baseada no conhecimento dos mais diversos elementos que compõem aquela sociedade:

O estudo de Aimorés, revela, assim, um campo vastíssimo para a atuação do educador sanitário. A importância dessa atuação, entre nós, avulta dia a dia, à proporção que os estudos sociológicos e antropológicos revelam o abismo existente entre a mentalidade 
rural e a mentalidade urbana. Enquanto as populações do campo permanecerem no atual estágio de desenvolvimento tecnológico, presas a um conjunto mitológico de símbolos inteiramente divorciado do contexto urbano, ligadas a formas sociais em que predomina o contato pessoal, a amizade, a proteção, será o educador sanitário o elo de união entre a Medicina Científica e a Medicina Popular. Sobre ele recairá a tarefa importantíssima de interpretar e modificar os hábitos sanitários das populações rurais. (Fontenelle, 1959, p. 102).

Embora valorize a cultural local e, particularmente, a medicina popular, Fontenelle é ambivalente ao abordar o papel do educador sanitário. Em face do processo de desenvolvimento em curso, caberia aos agentes de saúde mudarem as práticas sanitárias da população na medida em que a dinâmica da mudança social era irreversível.

\section{Considerações finais}

O tema da resistência à mudança como obstáculo ao desenvolvimento, sobretudo nas áreas rurais, esteve presente na agenda de cientistas sociais. Alguns deles, como vimos ao longo do texto, consideraram a saúde um importante tema para diagnosticar o que era visto na época como atraso e os meios necessários para se atingir a modernidade.

Florestan Fernandes, a partir da leitura da obra de Júlio Paternostro, analisa a complexa relação entre medicina popular e medicina científica revelando sensibilidade para o entendimento da prática médica. A modernização requeria recursos racionais de pensamento e ação e esbarrava em obstáculos de natureza cultural. É sob esta ótica que o livro de Paternostro desperta o interesse do sociólogo.

Willems defende um programa de intervenção política nas “culturas sertanejas", baseado em especialistas de diferentes áreas e 
com forte peso das ciências sociais. Apenas o conhecimento oriundo das ciências sociais permitiria uma ação orientada no sentido de alterar práticas culturais de forma congruente com o meio em que se inseriam. A desconsideração desse universo cultural mais amplo poderia, no limite, gerar situações de miséria diante das quais "mil vezes preferível" a "existência vegetativa" das populações sertanejas, por mais que elas afrontassem o "espírito capitalista" (Willems, 1944, p. 12).

No caso dos cientistas sociais do Sesp, que estavam voltados para a formação dos educadores sanitários, José Arthur Rios propõe que o cientista social, em meio aos conflitos que surgem entre médicos e outros especialistas do Sesp e a população, seja um intérprete que traduza a cultura da população pobre para os "termos racionais e científicos do grupo cultural que o administrador representa" (Rios, 1953). Só esse conhecimento permitiria um processo de mudança cultural.

Fontenelle tem uma posição crítica em relação aos serviços do Sesp. Não destoa de uma série de cientistas sociais que trabalhavam na América Latina com programas de saúde pública em que se procurava verificar os fracassos nas relações entre serviços de saúde e a população rural. O desprezo pela medicina popular dificultava o trabalho dos centros de saúde. Fontenelle tem uma visão abrangente do desenvolvimento. Não obstante ter uma perspectiva simpática à medicina popular, diagnostica o atraso da população rural e a importância do papel do educador sanitário em sua "tarefa importantíssima de interpretar e modificar os hábitos sanitários das populações rurais" (Fontenelle, 1959, p. 102).

Verificamos que a visão dos cientistas sociais acerca da inserção das comunidades rurais segundo a lógica e o modo de vida do mundo moderno é tão positiva quanto inexorável, e todos os impedimentos econômicos e sociais deveriam ser superados. As 
mudanças nas condições de saúde das populações rurais estariam acompanhadas, principalmente, de intervenções econômicas, sanitárias e educacionais, condições essenciais para a manutenção de uma agenda de modernização, de desenvolvimento do país. A única nota destoante presente no texto é de Alceu Maynard de Araújo. Analisando problemas de grande diversidade e complexidade como as relações entre religião e práticas de cura, Medicina rústica tem, entre outros, o mérito de deslocar a atenção das "resistências culturais à mudança" para os equívocos dos que representavam a medicina ocidental.

\section{Notas}

1 Carta de Luiz Fernando Raposo Fontenelle e Carlos Alberto de Medina a Henrique Maia Penido, 12/12/1957, 6 p. Fundo Fontenelle (DAD/ COC/Fiocruz).

2 De acordo com Willems (1944, p. 13), a condição das populações sertanejas seria preferível “à verdadeira miséria, por exemplo, daqueles 300.000 lavradores norte-americanos cuja sorte nos descreveu John Steinbeck em As vinhas da ira".

3 A segunda edição do livro em que os resultados da pesquisa foram publicados omite o nome da cidade paulista objeto do trabalho de campo, tendo sido alterado o título para Uma vila brasileira: tradição e transição. Da primeira edição, a que não tive acesso, constava como anexo estudo antropométrico da elite política local, que, segundo alguns, não gostara de ver ressaltada a herança mestiça que portava. De acordo com Nelson Werneck Sodré, prefaciador da segunda edição, por incompreensão da natureza científica do trabalho de Willems, tivera de ser suprimido o nome da cidade em que se realizara o trabalho de campo e de ser criado um nome hipotético. Mesmo não se conhecendo com exatidão as razões que motivaram o problema, é interessante observar a proximidade que os estudos culturais ainda guardavam dos estudos antropométricos, característicos da antropologia física. 
4 Dados extraídos da entrevista com o antropólogo Luiz Fernando Raposo Fontenelle realizada por Nísia Trindade Lima e Marcos Chor Maio em 2007 e 2008.

Translators, interpreters or change enablers? Social sciences, sanitation and cultural resistances (1940-1960)

Abstract: This study aims to examine the relationship between social sciences and public health in Brazil privileging the role of sociologists and anthropologists who have placed themselves in the position of "translators" among health professionals and rural populations object of government action. Health education, sanitation, prevention and curative medicine, preventive medicine will be perceived as actions whose efficiency depends directly on the deep understanding of a more extensive and complex cultural universe than reality. That is the central position of social scientists in the planning of administrative actions aimed especially at the Brazilian rural population: their knowledge of the socio-cultural in nature should anticipate and guide any interventions.

Keywords: Brazilian Social Thought; History of Social Sciences in Brazil; Special Service of Public Health; development; rural sociology.

\section{Referências bibliográficas}

ESCOBAR, Arturo. La invención del tercer mundo. Bogotá: Editorial Norma, 1998.

ARRUDA, Maria Arminda do Nascimento. Revisitar Florestan. Revista Brasileira de Ciências Sociais, São Paulo, v. 11, n. 30, p. 11-15, fev. 1996.

BENCHIMOL, Jaime Larry. Febre amarela: a doença e a vacina, uma história inacabada. 2. ed. Rio de Janeiro: Fiocruz, Bio-Manguinhos, 2001. 
CAMPOS, André Luiz Vieira de. Políticas internacionais de saúde na Era Vargas: o Serviço Especial de Saúde Pública, 1942-1960. Rio de Janeiro: Ed. Fiocruz, 2006.

CORRÊA, Mariza (Org.). História da Antropologia no Brasil (19301960): testemunhos: Emílio Willems e Donald Pierson. Campinas: Ed. Unicamp, Vértice, 1987.

FARLEY, John. To cast out disease: a history of the International Health Division of the Rockefeller Foundation (1913-1951). Oxford: Oxford University Press, 2004.

FERNANDES, Florestan. Ensaios de sociologia geral e aplicada. 3. ed. São Paulo, Pioneira, 1976.

FERNANDES, Florestan. Um retrato do Brasil. In: . Mudanças sociais no Brasil. 3. ed. São Paulo: Difel, 1979.

FONTENELLE, L. F. Raposo. Aimorés: análise antropológica de um programa de saúde. Rio de Janeiro: DASP, Serviço de Documentação, 1959.

FOSTER, G. M. et al. A cross-cultural anthropological analysis of a technical aid program. Washington, DC: Smithsonian Institution, 1951.

HOCHMAN, Gilberto. From autonomy to partial alignment: National Malaria Programa in the time of global erradication, Brazil, (19411961). Canadian Bulletin of Medical History, v. 25, n. 1, p. 161192, 2008.

KUBITSCHEK, Juscelino. Programa de saúde pública do candidato. São Paulo: L. Nicollini, 1955.

LIMA, Nísia Trindade de. Um sertão chamado Brasil: intelectuais e representação geográfica da identidade nacional. Rio de Janeiro: Revan, Iuperj, Ucam, 1999.

LOWY, Ilana. Virus, mosquitos e modernidade: a febre amarela no Brasil entre ciência e política. Rio de Janeiro: Ed. Fiocruz, 2006. 
MAIO, Marcos Chor. O Projeto UNESCO e a agenda das ciências sociais no Brasil dos anos 40 e 50. Revista Brasileira de Ciências Sociais, São Paulo, v. 14, n. 41, p. 141-158, 1999.

MAIO, Marcos Chor; VILLAS-BÔAS, Gláucia (Orgs.). Idéias de Modernidade e Sociologia no Brasil. Porto Alegre: Ed. UFRGS, 1999.

MICELI, Sérgio (Org.). História das ciências sociais no Brasil. São Paulo: Ed. Revista dos Tribunais, 1989.

MYRDAL, Gunnar. Economic aspects of health. WHO Chronicle, Genève, n. 6, p. 203, 1952.

PATERNOSTRO. Júlio. Viagem ao Tocantins. São Paulo: Companhia Editora Nacional, 1945. (Coleção Brasiliana, série 5, v. 248).

PIERSON, D. Algumas atividades em prol da antropologia e outras ciências sociais. In: CORRÊA, M. (Org.). História da antropologia no Brasil. São Paulo: Ed. Unicamp, Vértice, 1987.

REGISTER to the Records of the Institute of Social Anthropology, Smithsonian Institution, 1942-1952. Suitland, MD, National Anthropological Archives, Smithsonian Institution, [1952]. Disponível em: $<$ http://www.nmnh.si.edu/naa/fa/isa.pdf $>$.

RIOS, José Arthur. Ciências sociais e saúde pública. Boletim do Sesp, n. 38, p. 2-3, set. 1953.

. A saúde como valor social. Boletim do Sesp, n. 33, p. 2-3, abr. 1953a.

. Educação de grupos. Rio de Janeiro: SNES, 1954.

SESP e as ciências sociais (O). Boletim do Sesp, fev. 1945.

SOPER, Fred. The geographical distribution of imunity to yelow fever in man of South América. American Journal of Tropical Medicine, Baltimore, v. 17, n. 4, p. 457-511, 1937.

VALLADARES, Lícia do Prado. A invenção da favela: do mito de origem à favela. Rio de Janeiro: FGV, 2005. 
VILHENA, Luís Rodolfo. Os intelectuais regionais: os estudos de folclore e o campo das ciências sociais nos anos 50. Revista Brasileira de Ciências Sociais, São Paulo, v. 11, n. 32, p. 125-150, 1996.

VILLAS-BÔAS, Gláucia. Mudança provocada: passado e futuro no pensamento sociológico brasileiro. Rio de Janeiro: Ed. FGV, 2006.

WAGLEY, Charles. A study of man in the tropics. New York: MacMillan, 1953.

WILLEMS, Emílio. Assimilação e populações marginais no Brasil: estudo sociológico dos imigrantes germânicos e seus descendentes. São Paulo: Companhia Editora Nacional, 1940.

. O problema rural do ponto de vista antropológico. São Paulo: Secretaria da Agricultura, Indústria e Comércio do Estado de São Paulo, 1944.

. Uma vila brasileira: tradição e mudança. São Paulo: Difusão Européia do Livro, [1947] 1961.

WINSLOW, C.-E. A. Lo que cuesta la enfermidad y lo que vale la salud. Washington: Organizacion Mundial de la Salud, Oficina Sanitária Panamericana, 1955. (Publicaciones Cientificas, 16). 